\title{
Việt Nam tăng trưởng nhanh nhất khu vực Nam và Đông Nam Á về công bố khoa học
}

\author{
VietNamNet News
}

- Việt Nam tăng trưởng nhanh nhất trong khi Singapore, Ấn Độ và Pakistan có tổng sản lượng nhiều nhất về kết quả công bố khoa học.

Đây là thông tin đưa ra theo một công bố ngày 2-10-2019 vừa qua của ISI Clarivate Web of Science (ISI) về kết quả công bố khoa học của 14 nước tại khu vực Nam và Đông Nam Á, bao gồm: Lào, Myanmar, Brunei, Campuchia, Sri Lanka, Philippines, Bangladesh, Indonesia, Thái Lan, Pakistan, Malaysia, Singapore, Ân Độ và Việt Nam trong giai đoạn 1981-2018.

Nghiên cứu có tiêu đề Global Research Report - South and East Asia (tạm dịch: Báo cáo nghiên cứu toàn cầu tại Nam và Đông Nam Á), do 4 nhà khoa học đang làm việc cho ISI bao gồm Jonathan Adams, Gordon Rogers, Martin Szomszor và David Pendlebury thực hiện đã chỉ ra những vấn đề cố hữu của các nhà nghiên cứu tại khu vực này, bao gồm: có đóng góp đáng kể cho khoa học thế giới nhưng chủ yếu lại nhờ vào quãng thời gian họ làm việc tại nước ngoài.

Mặc dù vậy, năng lực nghiên cứu của khu vực đã có sự tăng trưởng vượt bậc và ngày càng có nhiều đóng góp quan trọng đối với khoa học thế giới. Trong những năm gần đây, trung bình mỗi năm, các nhà khoa học từ khu vực này đã công bố $8 \%$ tổng sản lượng công bố khoa học toàn cầu. Đây là kết quả ấn tượng nếu so với con số tương ứng chỉ khoảng $3 \%$ trong suốt giai đoạn 1981-1995.

Trong các nước thuộc khu vực, Việt Nam có sự tăng trưởng nhanh nhất, với lượng công bố tăng đã tăng gấp năm lần kể từ năm 2009.

Sự tăng trưởng của sản lượng công bố tại Nam và Đông Nam Á có sự đóng góp đáng kể từ quá trình hợp tác với nhau và với các nền khoa học phát triển hơn.

Theo đánh giá của nhóm tác giả, sự hợp tác tốt này là nhờ thông tin về các hội nghị được tiếp cận dễ dàng hơn, việc di chuyển cũng thuận tiện hơn; các dự án quốc tế trong các lĩnh vực lớn hiện nay như sức khoẻ, môi trường, hay vật lý cũng cung cấp thêm nhiều cơ hội cho các nhà khoa học; và đặc biệt là tính chất toàn cầu của các vấn đề khoa học.

Mạng lưới hợp tác quốc tế của khu vực Nam và Đông Nam Á được thể hiện ở hình dưới. Có thể thấy, Việt Nam có sự kết nối với hầu hết các nền khoa học phát triển trên thế giới như Mỹ, Pháp, Anh, hay trong châu Á như Nhật Bản, Đài Loan, Trung Quốc hay Hàn Quốc. 


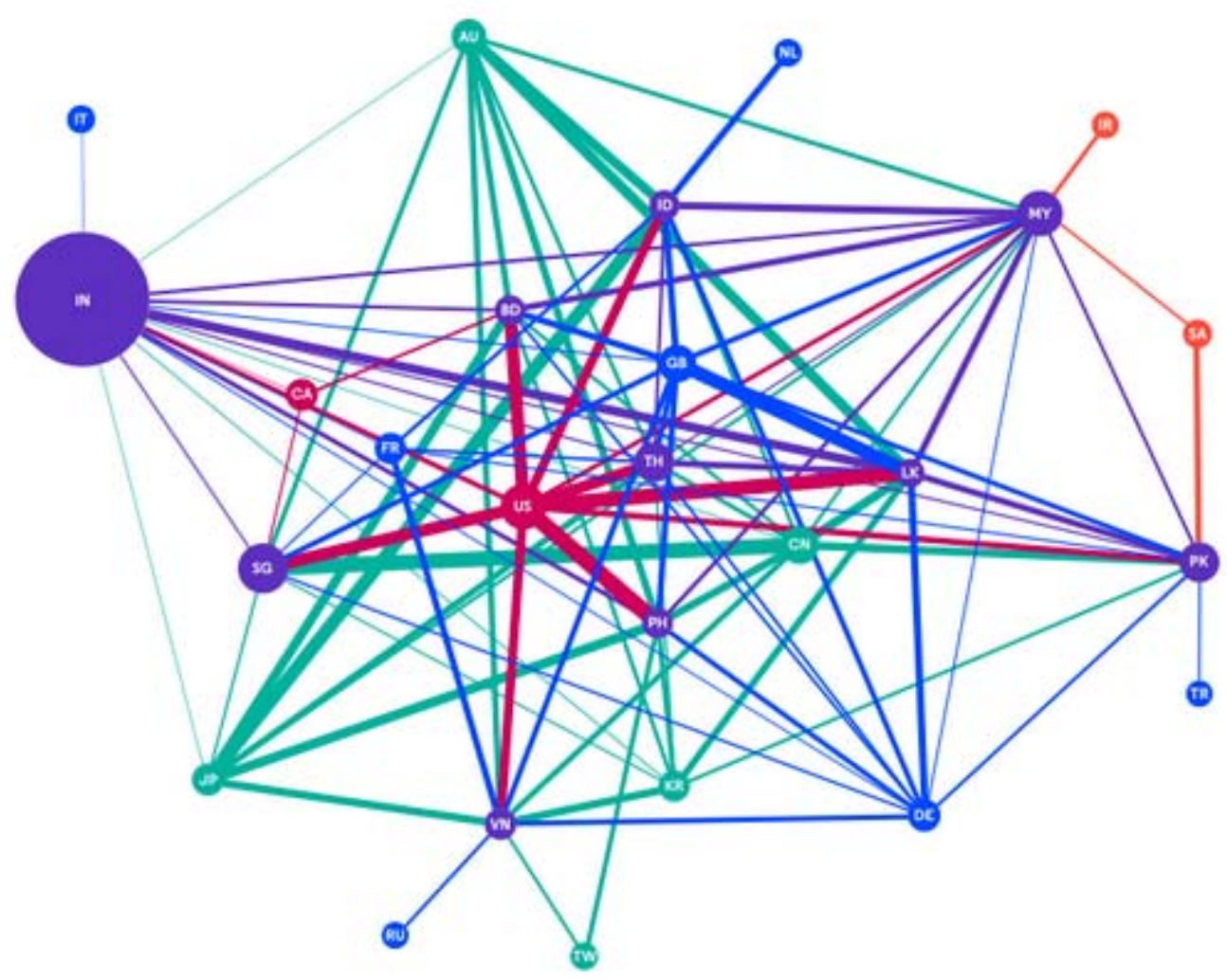

Mạng lưới hợp tác nghiên cứu giữa các nước thuộc khu vự Nam và Đông Nam Á với các nước tiên tiến trên thế giới (Nguồn: Báo cáo Global Research Report - South and East Asia)

Về mặt sản lượng công bố, Singapore vẫn luôn là một ngoại lệ tại khu vực với 2 đại học luôn nằm trong top đầu thế giới là Đại học Quốc Gia Singapore NUS và Đại học Công nghệ Nanyang NTU.

Trong giai đoạn 1981-2018, nước này đóng góp hơn 120,000 bài báo được ISI chỉ mục, chỉ sau Ấn Độ (hơn 560,000 bài báo). Mặc dầu vậy, cũng theo báo cáo Ấn Độ, vẫn đang được xem là "người khổng lồ ngủ quên" với rất nhiều tiềm năng phát triển.

Sau Ấn Độ, Singapore, các nước có sản lượng công bố lớn trong khu vực bao gồm: Malaysia (hơn 91,000 bài), Pakistan (hơn 77,000 bài), Thái Lan (hơn 70,000 bài), Việt Nam (hơn 26,000 bài).

Sự tăng trưởng tương đối nhanh về sản lượng công bố khoa học của khu vực Nam và Đông Nam Á cho thấy một tín hiệu tốt; song hành với sự phát triển và tiềm năng kinh tế của khu vực.

Với riêng Việt Nam, tốc độ tăng trưởng nhanh, thậm chí là nhanh nhất trong khu vực rõ ràng cũng đã phản ánh chính sách hội nhập quốc tế trong nghiên cứu và giáo dục đại học ở nước ta trong hơn 10 năm qua.

Một điểm đáng lưu ý, mốc 2009 - mốc ghi dấu sự tăng trưởng đột biến của Việt Nam trong báo cáo này cũng trùng với mốc chính thức bước vào hoạt động của Quỹ Phát triển Khoa học và Công nghệ Quốc Gia NAFOSTED (năm 2008). Theo nhận định của nhóm tác giả, Việt Nam vẫn còn có nhiều dư địa để phát triển nhanh hơn và hội nhập sâu hơn với thế giới về khoa học công nghệ trong những năm tiếp theo. 


\section{Vietnam}

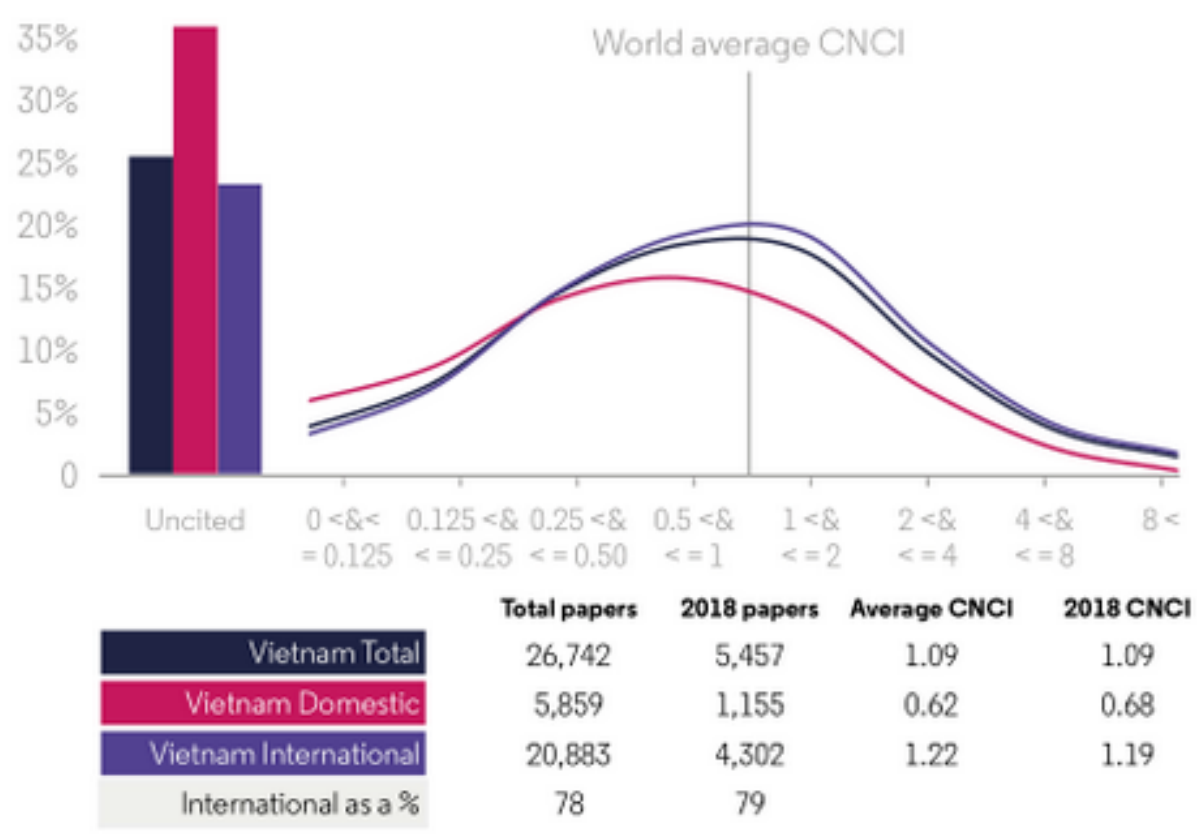

Kết quả công bố nghiên cứu của Việt Nam (Nguồn: Báo cáo Global Research Report - South and East Asia) 


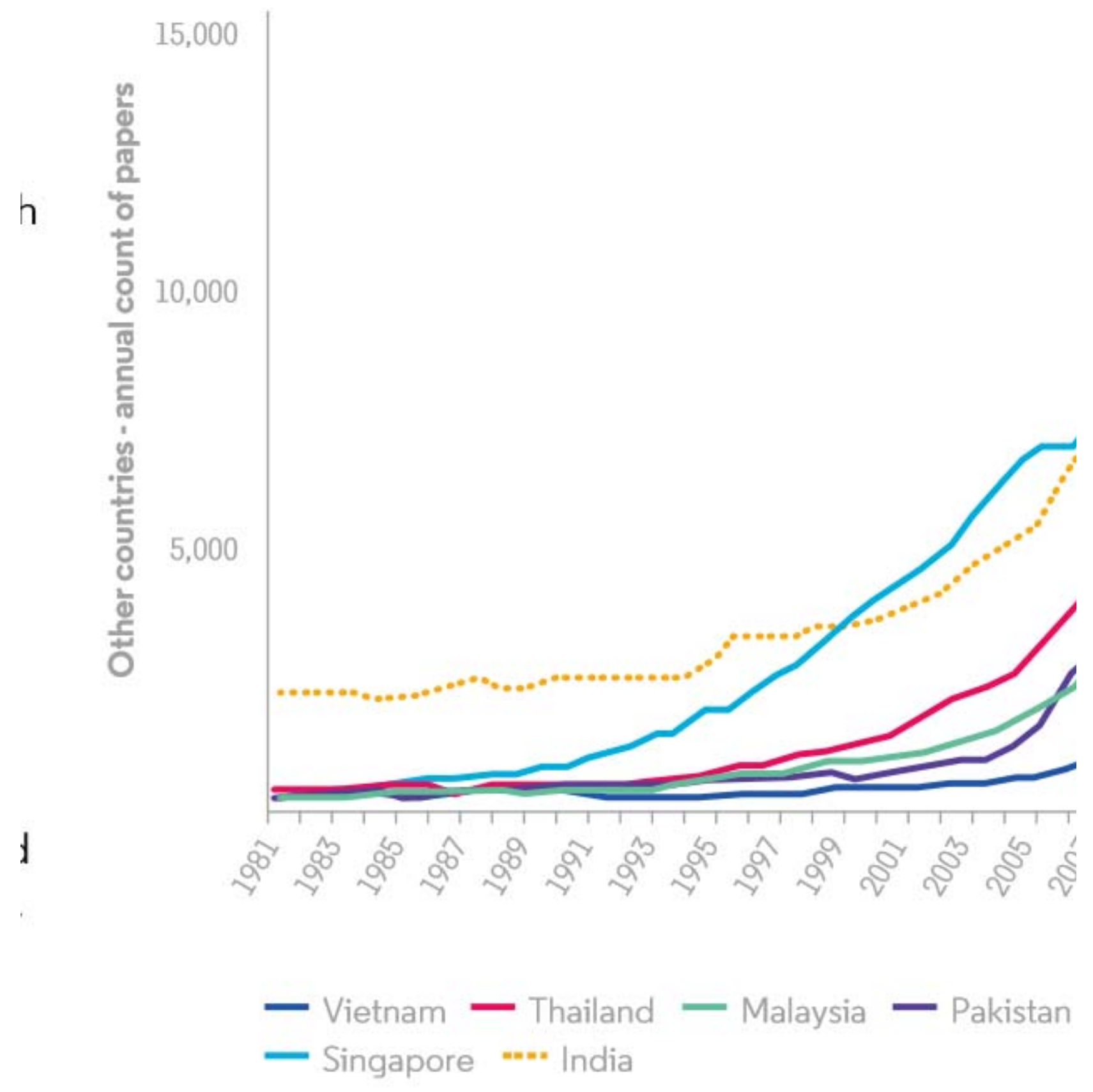

Công bố của 6 nước hàng đầu khu vực Nam và Đông Nam Á qua các năm (Nguồn: Báo cáo Global Research Report - South and East Asia)

Global Research Reports là một chuỗi báo cáo phân tích chuyên sâu về kết quả nghiên cứu do ISI thực hiện. Trước báo cáo Global Research Report - South and East Asia lần này, cũng trong năm 2019, ISI đã công bố 2 báo cáo khác trong chuỗi nghiên cứu, bao gồm: Global Research Report Profiles not Metrics và Global Research Report - G20 Scorecards. Riêng tại báo cáo Global Research Report - South and East Asia lần này, nhóm tác giả đã tham khảo một số nghiên cứu từ Việt Nam, bao gồm:

Nguyen T V, Ho-Le T P and Le U V. (2017). International collaboration in scientific research in Vietnam: an analysis of patterns and impact. Scientometrics, 110, 1035-1051 
Nguyen T V and Pham L T. (2011). Scientific output and its relationship to knowledge economy: an analysis of ASEAN countries. Scientometrics, 89, 107-117.

Phuong T T, Duong H B and McLean G N. (2015). Faculty development in Southeast Asian higher education: a review of literature. Asia Pacific Education Review, 16, 107-117.

Vuong Q H. (2019). The harsh world of publishing in emerging regions and implications for editors and publishers: The case of Vietnam. Learned Publishing, 32(4), 314-314; DOI:

10.1002/leap.1255

Trong đó, hai bài viết của tác giả Nguyễn Văn Tuấn là các nghiên cứu trắc lượng khoa học về Việt Nam và các nước ASEAN. Hai tác phẩm còn lại các các bài rà soát tổng quan chi tiết về phát triển đội ngũ giảng viên tại giáo dục đại học Đông Nam Á, và sự phát triển của xuất bản học thuật tại Việt Nam. Với tính chất là một báo cáo toàn cầu, các tác phẩm được nhóm tác giả gợi ý chắc hẳn đều có tính đại diện cao, chạm đến một cách đầy đủ các vấn đề về nghiên cứu và phát triển học thuật tại mỗi quốc gia.

Hồ Mạnh Toàn - Phạm Hiệp (SSHPA)

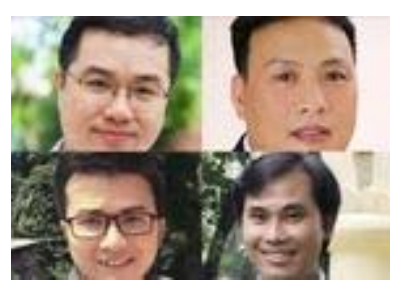

\section{0 nhà khoa học Việt Nam có trích dẫn nhiều trên thế giới}

Thông tin này do TS. Lê Văn Út, Trưởng phòng Phòng Quản lý Phát triển Khoa học Công nghệ và Trưởng .... 